\title{
Restraint required
}

DOI:

10.1038/nrc2082

\section{URLs}

p53

http://www.ncbi.nlm.nih.gov/ entrez/query.fcgi?db=gene\&c $\mathrm{md}=$ Retrieve\&dopt=full report\&list_uids $=7157$

\section{MDM2}

http://www.ncbi.nlm.nih.gov/ entrez/query.fcgi?db=gene\&c $\mathrm{md}=$ Retrieve\&dopt=full reportElist_uids=4193

\section{ARF}

http://www.ncbi.nlm.nih.gov/ entrez/query.fcgi?db=gene\&c $\mathrm{md}=$ RetrieveEdopt=full report\&list_uids $=102$
Components of the p53 tumoursuppressor pathway are often mutated in human tumours, making them potential therapeutic targets. As p53 is continuously degraded through its interaction with the ubiquitin ligase MDM2, removing this restraint has been one obvious means of increasing p53 expression levels in tumours with wild-type p53. Although small-molecule inhibitors that achieve this aim are now in preclinical trials, recent results from Gerard Evan and colleagues have indicated that this approach could be problematic.

In vitro data indicate that tumour cells can activate p53 if its expression is restored because signals that activate p53 are maintained in these cells, whereas such signals are likely to be low in normal cells, providing a window of therapeutic opportunity. Evan and colleagues, using their p53ER ${ }^{\mathrm{TAM}}$ knockin mice $\left(\operatorname{Tr} p 53^{\mathrm{KI} / K \mathrm{KI}}\right)$, which express a regulatable form of the $\mathrm{p} 53$ protein that can be switched (through the administration of 4-hydroxytamoxifen; 4OHT) between a null and wild-type state, have examined the activity of p53 in vivo in normal tissues of mice that lack MDM2.

The restoration of p53 functionality in all tissues - through the systemic administration of $4 \mathrm{OHT}$ - in adult $\operatorname{Tr} p 53^{\mathrm{KI} /}$ mice on an $M d m 2$-null background results in

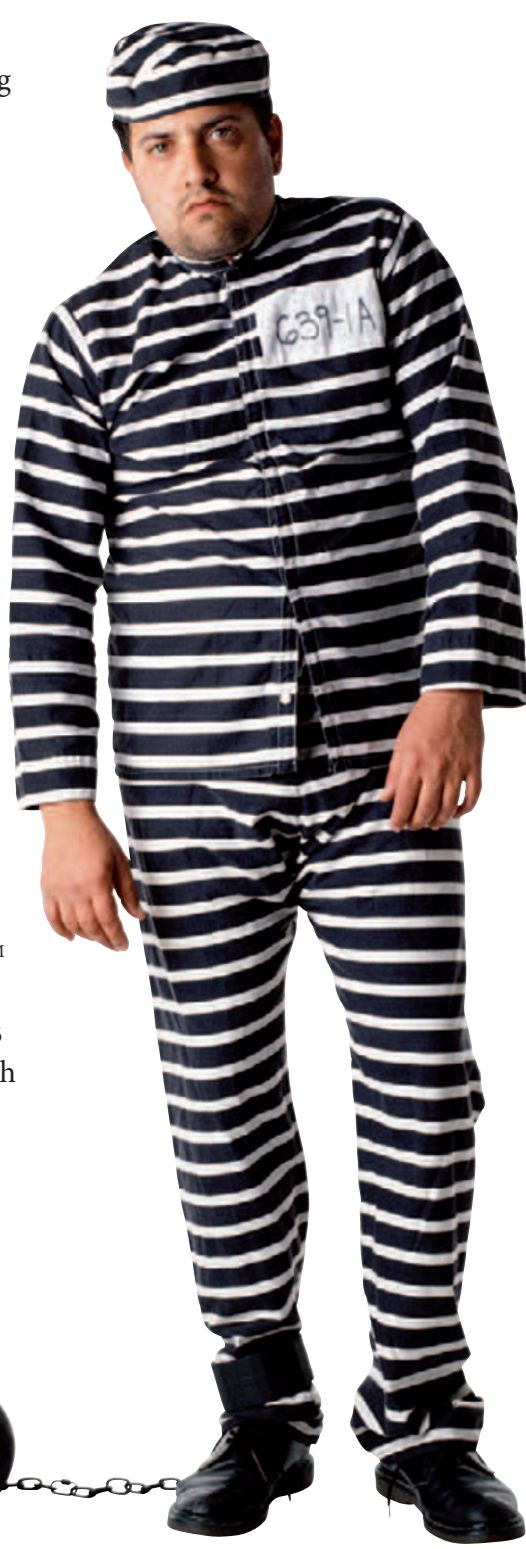

their death within 5-6 days. High levels of apoptosis are induced in tissues that are radiosensitive, such as bone marrow, thymus and spleen, and profound growth arrest is induced in radioresistant tissues such as the liver. There is no evidence that DNAdamage signalling pathways are active in these tissues, nor is p53 activity being mediated through the tumour suppressor ARF, which activates p53 in response to oncogenic stress. Moreover, under these conditions p53 is not subject to serine 18 phosphorylation, a post-translational modification that is typically associated with p53 activation. Therefore, the complete absence of MDM2 seems to be all that is needed for $\mathrm{p} 53$ to be fully and lethally active in tissues, suggesting that a complete blockade of the p53-MDM2 interaction is probably not a good idea therapeutically.

Nonetheless, small molecules such as Nutlin 3, which inhibit the interaction between p53 and MDM2, have shown significant anti-tumour effects in mice with no obvious side effects. This might be because Nutlin 3 does not completely inhibit the interaction of p53 with MDM2, leaving p53 susceptible to some degree of regulation.

Clearly, we need to know more about the interaction and regulation of $\mathrm{p} 53$ by MDM 2 to better understand how to manipulate this component of the p53 pathway.

\section{Nicola McCarthy}

ORIGINAL RESEARCH PAPERS Ringshausen,

O'Shea, C. C., Finch, A. J., Brown-Swigart, L. \& Evan, G. I. Mdm2 is critically and continously required to suppress lethal $\mathrm{p} 53$ activity in vivo. Cancer Cell 10, 501-514 (2006) 